\title{
Insight and Relationship Satisfaction as Predictors of the Life Satisfaction of a Community Sample of Adults
}

\author{
Elif Cimsir \\ Department of Guidance \& Counseling \\ Faculty of Education, Anadolu University, Eskisehir 26470, Turkey
}

\begin{abstract}
As a complex construct that is characterized by different dimensions such as selfunderstanding and self-acceptance, insight has long been suggested to be a predictor of greater life satisfaction. However, research is scarce when it comes to the underlying dynamics of the relationship between insight and life satisfaction. Thus, a mediation model is hypothesized in this study wherein increased insight is proposed to be connected to greater life satisfaction through an increased level of romantic relationship satisfaction. A sample of 244 adults (147 females and 97 males) with a mean age of 34.88 filled out the Insight Scale, the Life Satisfaction Scale and the Relationship Assessment Scale. Although no indirect effect of relationship satisfaction was found between insight and life satisfaction, the results indicated that both insight $(\mathrm{r}=.36)$ and romantic relationship satisfaction $(\mathrm{r}=.43)$ are significantly correlated with life satisfaction. Furthermore, almost $30 \%$ of the total variance in life satisfaction was explained by the regression model featuring insight and romantic relationship satisfaction as predictors. Implications for the fields of counseling and education are discussed.
\end{abstract}

Keywords: Insight, Relationship Satisfaction, life Satisfaction, 